the section on birds and mammals about which groups good books in English already exist. These sections appear to be the most reliable and better parts of this book.

The colour plates of birds, $1-4$, are fair; those of beetles, 5 and 6 , are poor; those of butterflies and moths, 7-9, are fair; plate 10 depicts 36 Lepidoptera larvae, some readily recognisable. The 14 diragonflies on plate 13 are passable. Plate 14 of various Hymenoptera and Diptera is almost useless. No reference is given to the page opposite which each plate occurs, thus making it irritatingly difficult to locate a plate. The figures of the invertebrates are of variable quality but many could be much better.

As stated in the foreword this book 'will help the amateur to recognise any wild animals, birds and insects which he may encounter'. But it will also mislead, and it will certainly not be of much use to the advanced student. The translation is quite good.

JOHN SANKEY

The drawing, one of many in the book, is of a beech marten.

\title{
The Oxford Book of Insects by John Burton. Oxford University Press, 50s.
}

This book has been designed as an introduction to the insect life of the British Isles, with colour illustrations of some 780 different species. It is true that this is a small percentage of the 20,000 or more insects so far recorded in this country, but the vast majority of these are never likely to be seen by the layman. The species illustrated have been very well selected and provide representative examples from all the insect groups found in Britain. The quality of the illustrations is exceedingly high, particularly in the case of the butterflies and moths which of course lend themselves to this treatment. Most of the pictures are life size, but where this is not so, great care has been taken to indicate the actual size.

Opposite each colour plate there are well-written notes on each species illustrated, providing a great deal of information on distribution, general habits and breeding biology. This is particularly useful in the case of the lesser-known groups such as bristle-tails, thrips, spring-tails and stoneflies, which are difficult to find out about unless one has access to specialist journals.

The publication of this single volume covering the Insecta is indeed welcome as this is undoubtedly the best way of conveying to the amateur naturalist an idea of the wealth of form and adaptation presented by this vast group of animals.

H. G. VEVERS

\section{Ecological Adaptations for Breeding in Birds by David Lack. Methuen, 84s. New York, Barnes \& Nobel.}

Over the last few years naturalists whose interests embrace both ecology and ethology have gradually become aware of something that now seems almost too obvious to be worth mentioning - that all aspects of the natural history of a species are interrelated; none can be fully understood in isolation. How these interrelations work is beginning to be understood in some vertebrate species, especially in birds, because more people have studied them than the other 